\title{
СРАВНИТЕЛЬНЫЙ АНАЛИЗ ФОРМИРОВАНИЯ НЕДВИЖИМОГО ИМУЩЕСТВА В РОССИЙСКОЙ ФЕДЕРАЦИИ И ШВЕЦИИ
}

\section{Евгения Андреевна Сивоконь}

Сибирский государственный университет геосистем и технологий, 630108, Россия, г. Новосибирск, ул. Плахотного, 10, обучающийся, тел. (983)132-65-54, e-mail: eva.sivokon@mail.ru

\section{Виктор Николаевич Клюшниченко}

Сибирский государственный университет геосистем и технологий, 630108, Россия, г. Новосибирск, ул. Плахотного, 10, кандидат технических наук, доцент кафедры кадастра и территориального планирования, тел. (913)450-94-57, e-mail: kimirs@yandex.ru

Актуальность выбранной темы обусловлена тем, что в настоящее время в мире существует 25 так называемых богатых стран. Все они характеризуются наличием систем земельного кадастра, обеспечивающего надежные гарантии для обладателей прав на землю. В соответствии с этим возникает необходимость в сравнительном анализе формирования недвижимого имущества в РФ и зарубежных странах, с целью разработки путей совершенствования отечественного кадастра.

Целью работы является выработка рекомендаций по совершенствованию отечественного кадастра на основании выполненного сравнительного анализа.

Ключевые слова: Государственный кадастровый учет, Государственная регистрация прав, Земельный кодекс, объекты недвижимости, формирование недвижимости

\section{COMPARATIVE ANALYSIS OF THE FORMATION REAL ESTATE IN THE RUSSIAN FEDERATION AND SWEDEN}

\section{Eugene A. Sivokon}

Siberian State University of Geosystems and Technologies, 10, Plakhotnogo St., Novosibirsk, 630108, Russia, Student, phone: (983)132-65-54, e-mail: eva.sivokon@mail.ru

\section{Viktor N. Klyushnichenko}

Siberian State University of Geosystems and Technologies, 10, Plakhotnogo St., Novosibirsk, 630108, Russia, Ph. D., Associate Professor, Department of Cadastre and Territorial Planning, phone: (913)450-94-57, e-mail: kimirs@yandex.ru

The relevance of the chosen topic is due to the fact that there are currently 25 so-called rich countries in the world. All of them are characterized by the existence of land cadastre systems that provide reliable guarantees for land rights holders. In accordance with this, there is a need for a comparative analysis of the formation of real estate in the Russian Federation and foreign countries, in order to develop ways to improve the domestic cadastre.

The purpose of this work is to develop recommendations for improving the national cadastre based on the comparative analysis performed.

Keywords: State cadastral registration, State registration of rights, Land code, real estate objects, formation of real estate 
Государственный кадастровый учет земельных участков как информационная система, призван отражать качество земли как природного объекта, служить источником информации при осуществлении государственного контроля за использованием и охраной земель. В то же время деятельность по ведению кадастра недвижимости должна быть законным средством обеспечения учета плательщиков земельного налога, определения размера земельных платежей и основой для получения первичной информации при кадастровой оценке.

Создание единой системы регистрации прав базируется на сложившемся положительном многолетнем опыте функционирования систем государственной регистрации прав и государственного кадастрового учета недвижимости, а также на учете современной международной практики развития предоставления услуг в этих сферах, которая свидетельствует о перспективности интеграции систем и внедрения новых информационных технологий, снижающих издержки пользователей и государства при оказании соответствующих услуг.

Центральным звеном правового регулирования создания единой системы государственной регистрации недвижимости является Федеральный закон от 13 июля 2015 года № 218-Ф3 «О государственной регистрации недвижимости», вступивший в силу с 1 января 2017 года, ключевыми положениями которого являются [1]:

- создание единого информационного ресурса - Единого государственного реестра недвижимости (ЕГРН), объединяющего реестр прав и кадастр недвижимости;

- внедрение единой учетно-регистрационной процедуры в случае образования и создания объекта недвижимости;

- экстерриториальность представления заявителями документов (в любой офис независимо от места нахождения недвижимости);

- осуществление учетно-регистрационных процедур, а также внесение иных сведений в ЕГРН в порядке межведомственного взаимодействия между органами власти и органом регистрации прав (без участия заявителя);

- особенности регистрации прав в случаях участия нотариусов в отношениях по регистрации прав;

- повышение ответственности учетно-регистрационной системы, в том числе за внесение недостоверных сведений в ЕГРН, включая установление четких пределов ответственности государственного регистратора прав;

- сокращение сроков кадастрового учета (до 5 дней) и регистрации прав (до 7 дней);

- порядок компенсации за утрату права собственности на жилье, зарегистрированного в Едином государственном реестре недвижимости.

В настоящее время в Швеции построена практически самая совершенная система управления земельными и имущественными ресурсами. В Швеции создана единая база данных свойств объектов недвижимости. Кроме того, в Швеции процесс земельного кадастра практически полностью автоматизирован. Поэтому опыт ведения земельного кадастра в этой развитой скандинавской стране перенимается другими странами. 
Важным элементом земельного кадастра Швеции является его четкая организационная структура. В то же время национальная земельная служба считается государственной организацией Министерства окружающей среды, которая выполняет функции, определенные правительством: она осуществляет национальные программы картирования страны, осуществляет государственный надзор за национальной кадастровой программой и осуществляет работу на местах, геодезии, топографии, кадастра и управления землепользованием, собирает и распространяет цифровые данные.

Ведущим государственным учреждением отрасли стала Национальная земельная служба Швеции (NLS). Направления деятельности NLS:

1. Разработка и реализация земельной политики.

2. Разработка и совершенствование земельного законодательства.

3. Планирование и использование земель.

4. Формирование земельных участков и других объектов недвижимости регистрация прав на землю и другую недвижимость.

5. Оценка и налогообложение земель.

6. Создание и эксплуатация земельно-информационных и геоинформационных систем.

7. Проведение геодезических и картографических работ общегосударственного значения.

Учитывая многолетний опыт создания кадастра в развитых зарубежных странах, можно предположить, что для совершенствования кадастра России целесообразно приступить к созданию трехмерного кадастра подземных и наземных объектов; перевести все материалы в электронный вид; создать единую методологию внесения сведений о недвижимом имуществе, повысить точность определения координат границ до нескольких сантиметров.

Отечественной кадастровой системе присущ ряд проблем, отмеченных известными учеными [3]. Основные проблемы перечислены ниже, влияние которых рекомендуется уменьшить или полностью устранить в целях совершенствования национальной кадастровой системы.

Первая проблема связана с масштабностью работ по созданию собственности и нестабильностью нормативно-правовой базы в области кадастровой и кадастровой деятельности.

Вторая проблема заключается в том, что финансирование кадастра должно осуществляться на государственном уровне. Также целесообразно применять опыт некоторых зарубежных стран, который обеспечивает сбор налогов без привлечения средств заявителей.

Третья проблема - отсутствие в кадастре качественной информации о территориальных зонах, что затрудняет создание объектов недвижимости.

Еще одна проблема - несовершенство кадастровой оценки, что подтверждается многочисленными судебными разбирательствами. Следовательно, необходимо разработать надежную методологию кадастровой оценки, понятную владельцам недвижимости и исключающую судебные разбирательства для снижения кадастровой стоимости. 
Шестая проблема заключается в том, что кроме существующих доходов необходимо также ввести доходы от частных самолетов и судов внутреннего плавания. Таким образом, можно значительно пополнить бюджеты муниципалитетов и государства в целом.

Седьмая проблема - наличие ошибок в ЕГРН. В то же время не существует апелляционного института для беспристрастного разрешения споров, возникающих в связи с формированием недвижимости. Имеет смысл также установить личную ответственность за допущенные ошибки, как это реализуется в некоторых зарубежных странах.

Восьмой проблемой можно считать то, что пункты государственной геодезической сети утрачены на 60 \%. Поэтому необходимо создавать спутниковые системы для точного позиционирования, стоимость создания которых ниже, чем у эталонных пограничных сетей.

Девятая проблема - непрозрачность процедуры регистрации собственности для каждого объекта, информация которого зарегистрирована в реестре недвижимости, он имеет максимум пять-шесть основных характеристик. Другие характеристики могут быть вставлены в декларацию владельцев недвижимости или в процессе сделки с ним [4].

Анализируя принципы ведения кадастра и кадастровой деятельности в двух государствах можно отметить следующее: в РФ что продолжает оставаться актуальным вопрос налогообложения земельных долей, выраженных в гектарах или баллах, поскольку до настоящего времени постановление Правительства Российской Федерации, предусмотренное пунктом 4 статьи 15 Федерального закона «Об обороте земель сельскохозяйственного назначения», не принято, что, в свою очередь, не позволяет также обеспечить внесение необходимых сведений в ЕГРН.

В Швеции законодательство закрепляет два вида владельческих исков иски о возврате вещи и иски об устранении нарушений владения. В Швеции права на недвижимость и право подачи владельческих исков принадлежат только лицам, зарегистрированным в соответствующем реестре. Такая система защиты обеспечивает подтверждение существующих прав [5]. Таким образом, государственная регистрация прав является основным доказательством существования прав на объект недвижимости. При этом в Швеции Градостроительное Уложение сдерживает владельца от насильственных действий по отношению к мошенникам.

Таким образом, сравнивая формирование недвижимого имущества в РФ и Швеции, могу сказать, что в Российской государственной учетно-регистрационной системе отсутствует гарантия прав собственности физических и юридических лиц на недвижимость, а добросовестный владелец не защищен должным образом от притязаний третьих лиц. Поэтому целесообразно ввести условия полного признания принципа публичной достоверности данных. На основании сравнительного анализа формирования недвижимого имущества в РФ и Швеции, можно сделать вывод о том, что законодательство в сфере 
формирования недвижимого имущества в Российской Федерации целесообразно изменить по направлениям:

- расширить сферу защиты прав собственности на недвижимое имущество путем введения правовой экспертизы документов, представленных заявителями;

- законодательно закрепить порядок гражданской защиты и установить размер возмещения убытков, соответствующих стоимости утраченного имущества;

- предусмотреть законодательные санкции за преднамеренные ошибки, допущенные в материалах кадастровой деятельности;

- сократить перечень условий приостановления проведения ГКУ;

- повысить достоверность данных, содержащихся в ЕГРН путем незамедлительного проведения комплексных кадастровых работ;

- раскрыть порядок использования денежных средств, получаемых от предоставления выписок из ЕГРН.

\section{БИБЛИОГРАФИЧЕСКИЙ СПИСОК}

1. Федеральный закон от 13.07.2015 г. № 218-Ф3 «О государственной регистрации недвижимости: федеральный закон» [Электронный ресурс]. - Доступ из справ. - правовой системы «КонсультантПлюс».

2. Недвижимость в Швеции (законодательство и сравнительный анализ) / В. А. Дорошкевич [и др.]; под общ.ред. В.А. Дорошкевича. - Минск: УП «Оргстрой», 2011. - 415 с.

3. Никонов П. Н., Журавский Н. Н. Недвижимость, кадастр и мировые системы регистрации прав на недвижимое имущество. Аналитический обзор. - СПб., 2006. - 110 с.

4. Официальный сайт Федеральной службы государственной регистрации, кадастра и картографии (Росреестр) [Электронный ресурс] - Режим доступа: http://www./rosreestr.ru.

5. Селивановская Ю. И., Сбоева И. М. К вопросу об ответственности за ненадлежащую правовую экспертизу документов при государственной регистрации прав на недвижимое имущество // Проблемы экономики и юридической практики. - 2017. - № 2. - С. 164-166.

(C) Е. А. Сивоконь, В. Н Клюшниченко, 2021 